\title{
Сравнительная динамика патентования в России и США
}

П. Мазуркин, д-р т. н., профессор, федеральный эксперт РИнкЦЭ, заведующий кафедрой природообустройства Поволжского государственного технологического университета (г. Йошкар-Ола)

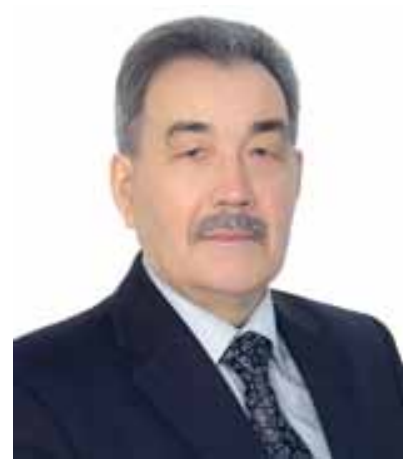

Дано сравнение статистических моделей динамики ежегодного патентования в США и России за 1992-2012 гг. Показана несовместимость инновационной политики двух стран по качеству патентования и необходимость кардинального изменения поведения России в области изобретательства. Дан прогноз соотношений числа патентов между двумя странами. Отмечена недостаточная точность исходных данных. По ежегодно итерационно идентифицируемым формулам можно давать инерционные сравнительные прогнозы количества изобретений.

\section{Ключевые слова:}

Россия и США, количество изобретений, многолетняя динамика, статистические модели, прогнозирование.
Keywords:

e 
В объеме патентов изобретения определяют мировую новизну продукции, а сравнение банков патентов позволяет оценить новые технологии. Комплекты изобретений позволяют защитить продукцию при экспорте.
Из статьи [1] приняты исходные данные по многолетней динамике патентования в США и России. По методике ${ }^{1}$ автором статьи проведено моделирование и по моделям даны прогнозные оценки (табл. 1) этих объемов.

Таблица 1

\section{Объем патентования изобретений в России и США}

\begin{tabular}{|c|c|c|c|c|c|c|c|}
\hline \multirow{2}{*}{ Год } & \multirow{2}{*}{$\begin{array}{c}\text { Время } \\
t, \text { лет }\end{array}$} & \multicolumn{2}{|c|}{ Объем патентования, шт. } & \multicolumn{2}{|c|}{ Отношение объемов } & \multirow{2}{*}{$\begin{array}{l}\text { Разница } \\
N_{\text {USA }}-N_{R U}\end{array}$} & \multirow{2}{*}{$\begin{array}{c}\text { Коэффиц. } \\
\text { К }\end{array}$} \\
\hline & & Россия $N_{R U}$ & США $N_{U S A}$ & $N_{R U} / N_{U S A}$ & $N_{\text {USA }} / N_{R U}$ & & \\
\hline 1 & 2 & 3 & 4 & 5 & 6 & 7 & 8 \\
\hline 1992 & 0 & 28783 & 107503 & 0,2677 & 3,7349 & 78720 & 2,7349 \\
\hline 1993 & 1 & 20290 & 113613 & 0,1786 & 5,5995 & 93323 & 4,5995 \\
\hline 1994 & 2 & 21904 & 119547 & 0,1832 & 5,4578 & 97643 & 4,4578 \\
\hline 1995 & 3 & 19294 & 134286 & 0,1437 & 6,9600 & 114992 & 5,9600 \\
\hline 1996 & 4 & 19397 & 148938 & 0,1302 & 7,6784 & 129541 & 6,6784 \\
\hline 1997 & 5 & 18158 & 167236 & 0,1086 & 9,2100 & 149078 & 8,2100 \\
\hline 1998 & 6 & 20108 & 179450 & 0,1121 & 8,9243 & 159342 & 7,9243 \\
\hline 1999 & 7 & 23785 & 194738 & 0,1221 & 8,1874 & 170953 & 7,1874 \\
\hline 2000 & 8 & 27842 & 233353 & 0,1193 & 8,3813 & 205511 & 7,3813 \\
\hline 2001 & 9 & 31869 & 246482 & 0,1293 & 7,7342 & 214613 & 6,7342 \\
\hline 2002 & 10 & 35377 & 253495 & 0,1396 & 7,1655 & 218118 & 6,1655 \\
\hline 2003 & 11 & 40232 & 262343 & 0,1534 & 6,5208 & 222111 & 5,5208 \\
\hline 2004 & 12 & 41935 & 276926 & 0,1514 & 6,6037 & 234991 & 5,6037 \\
\hline 2005 & 13 & 45651 & 286269 & 0,1595 & 6,2708 & 240618 & 5,2708 \\
\hline 2006 & 14 & 49295 & 283985 & 0,1736 & 5,7609 & 234690 & 4,7609 \\
\hline 2007 & 15 & 49956 & 280167 & 0,1783 & 5,6083 & 230211 & 4,6083 \\
\hline 2008 & 16 & 49879 & 263968 & 0,1890 & 5,2922 & 214089 & 4,2922 \\
\hline 2009 & 17 & 38275 & 240032 & 0,1595 & 6,2712 & 201757 & 5,2712 \\
\hline 2010 & 18 & 38450 & 184794 & 0,2081 & 4,8061 & 146344 & 3,8061 \\
\hline 2011 & 19 & 23252 & 71129 & 0,3269 & 3,0590 & 47877 & 2,0590 \\
\hline 2012 & 20 & 3752 & 1840 & 2,0391 & 0,4904 & -1912 & $-0,5096$ \\
\hline \multicolumn{8}{|c|}{ Горизонт прогноза } \\
\hline 2013 & 21 & -12988 & 119738 & 16,3597 & $-0,1638$ & -109084 & $-2,1075$ \\
\hline 2014 & 22 & -13021 & 1265786 & 124,4408 & 3,4564 & -230128 & $-17,0017$ \\
\hline
\end{tabular}

${ }^{1}$ См.: П. Мазуркин. Динамика российских изобретений//Интеллектуальная собственность. Промышленная собственность. - 2014. - № 2; Мазуркин П.М. Решение 23-й проблемы Гильберта. Междисциплинарные исследования в области математ. моделирования и информатики. Матер. 3-й научно-практ. internet-конф. - Ульяновск: SIMJET, 2014.; Мазуркин П. М. Вейвлет-анализ кризисной динамики курса рубля // Maтер. 3-й научно-практ. internet-конф. - Ульяновск: SIMJET, 2014. 


\begin{tabular}{|c|c|c|c|c|c|c|c|}
\hline 1 & $\mathbf{2}$ & $\mathbf{3}$ & $\mathbf{4}$ & $\mathbf{5}$ & $\mathbf{6}$ & $\mathbf{7}$ & $\mathbf{8}$ \\
\hline 2015 & 23 & 17177 & 1123460 & 868,4021 & $-0,0952$ & -376214 & $-8,3173$ \\
\hline 2016 & 24 & 134911 & 1097467 & 5581,457 & 3,6726 & -548890 & $-11,7538$ \\
\hline 2017 & 25 & 431031 & 1126950 & 33251,74 & 0,1121 & -751488 & $-20,3527$ \\
\hline 2018 & 26 & 1072626 & 1190600 & 184707,9 & $-2,4992$ & -986436 & $-21,6196$ \\
\hline 2019 & 27 & 2388752 & 1277457 & 961724 & 1,8262 & -1256237 & $-14,9971$ \\
\hline 2020 & 28 & 4983495 & 1381266 & 4715771 & 3,5875 & -1563317 & $-13,5663$ \\
\hline 2021 & 29 & 9996022 & 1502471 & 21868639 & $-1,9639$ & -1909983 & $-13,5342$ \\
\hline 2022 & 30 & 19614617 & 1640087 & 96272234 & $-3,3846$ & -2298386 & $-45,2638$ \\
\hline 2023 & 31 & 38062560 & 1792366 & $4,04 \mathrm{E}+08$ & $-3,5341$ & -2730456 & $-30,4376$ \\
\hline 2024 & 32 & 73663184 & 1961772 & $1,62 \mathrm{E}+09$ & 3,7187 & -3207849 & $-42,6307$ \\
\hline 2025 & 33 & $1,43 \mathrm{E}+08$ & 2149166 & $6,21 \mathrm{E}+09$ & $-3,3037$ & -3731870 & 15,4167 \\
\hline 2026 & 34 & $2,81 \mathrm{E}+08$ & 2354311 & $2,29 \mathrm{E}+10$ & $-1,8772$ & -4303395 & $-66,4011$ \\
\hline 2027 & 35 & $5,58 \mathrm{E}+08$ & 2580319 & $8,13 \mathrm{E}+10$ & 2,7531 & -4922781 & 31,4041 \\
\hline 2028 & 36 & $1,13 \mathrm{E}+09$ & 2828692 & $2,79 \mathrm{E}+11$ & 4,3191 & -5589765 & 52,4690 \\
\hline 2029 & 37 & $2,32 \mathrm{E}+09$ & 3100372 & $9,23 \mathrm{E}+11$ & 3,0809 & -6303343 & $-40,3255$ \\
\hline 2030 & 38 & $4,89 \mathrm{E}+09$ & 3398987 & $2,96 \mathrm{E}+12$ & 0,7353 & -7061643 & $-18,8997$ \\
\hline
\end{tabular}

В таблице 1 приняты условные обозначения: $t$ - время измерений, для 1992 г. принимается $t=0$ (лучше бы динамический ряд начать раньше, включив в него и советские времена, например с 1952 г.); $N_{R U}$ - ежегодное количество патентов, включая и на изобретения, в России, шт;; $N_{U S A}-$ аналогичный показатель США, шт.; $N_{R U} / N_{U S A}$ - отношение объемов патентов России к США; $N_{U S A} / N_{R U}$ - отношение объемов патентов США к России; $N_{U S A}-N_{R U^{-}}$разница между объемами патентов США и России; $K$ - кратность достижения Россией объема США, $K=\left(N_{U S A}-N_{R U}\right) / N_{R U}$. Далее рассмотрим шесть многочленных статистических закономерностей.

Объем патентования в России. Количество патентов в нашей стране изменяется по графикам на рисунке 1 по формуле:

$N_{R U}=N_{1}+N_{2}+N_{3}+N_{4}$,

$N_{1}=20137,366 \exp \left(0,0029067 t^{2,29800}\right)$,

$N_{2}=-3,70339 \cdot 10^{-5} t^{7,65749}$,

$N_{3}=A_{1} \cos \left(\pi t / p_{1}+0,80687\right)$,

$A_{1}=12501,360 \exp \left(-0,90186^{0,29987}\right)$,
$N_{4}=A_{2} \cos \left(\pi t / p_{2}+3,66117\right)$,

$A_{2}=7,22653 \cdot 10^{-68} t^{85,17581} \exp \left(-4,1339 t^{1,03752}\right)$,

$p_{2}=6,15466-0,20497 t^{0,96942}$,

где $A$ - амплитуда (половина) колебания, $p$ - полупериод (частота) колебания $1 / p$.

Первая составляющая (1) является законом экспоненциального роста в полной форме. Он является естественной частью тренда. А вторая составляющая показывает кризисное (отрицательный знак перед членом) изменение численности российских патентов. В итоге двухчленный тренд на рисунке 1 получает тенденцию увеличения с 1998-го по 2007 гг. Но после 2007 г. вторая кризисная составляющая начинает резко превышать естественный первый член уравнения (1). Поэтому интерес к инновациям у промышленности России неуклонно нарастает по первому члену (1), но этот интерес резко тормозится понижающимся уровнем качества патентования и уменьшающихся объемов востребования: в технической политике страны нет позитивных стимулов, а преобладают одни негативы. Осознание сильнейшего кризиса в инновационном развитии 
страны по второму члену уравнения (1) позволило бы принять соответствующие меры и сбавить темпы спада объема патентования.

Оба колебания позитивные (положительный знак перед составляющими), амплитуда первого колебания имеет спад, а второго - характер стрессового возбуждения. При этом первое волновое возмущение (рис. 1) резко учащается по частоте, что показывает потерю управляемости инновационными процессами. При полупериоде 7,24 года в 1992 г. учащение дойдет до одного года в 2019 г. и далее станет отрицательным по значению (половина амплитуды станет равной всего 1108 шт.). Таким образом, влиянием первого колебания с 2020 г. можно пренебречь. Второе колебание было показано в статье ${ }^{2}$. По формуле (1) и графику (рис. 1) эта волна закончится в 2015 г.

Получается, позитивные колебания завершатся в 2015 и 2019 гг. Начало нового положительного колебания в доктрине патентования пока не пред- видится: все остается так, как было в советские времена. Иначе говоря, нужно принять срочные меры по повышению качества патентования, чтобы каждый патент работал на конкурентоспособность отечественной продукции.

Если не будет повышено генотипическое расстояние ${ }^{3}$ от прототипа к изобретению, то по прогнозу из таблицы 1 и формулы (1) резко увеличится объем патентования, но при этом патенты не будут повышать мировой технический уровень выпускаемой отечественной продукции. В итоге, как и прежде, более $70 \%$ патентов будут направлены на морально устаревшие технику и технологии. С 2017 г. объем патентования в ФИПС достигнет до кризисного 2007 г., но каждый патент будет иметь очень малые приращения по новизне, комплексности технического решения, генотипическому расстоянию от прошлых патентов. Для коренной реформы промышленности и действительного перехода к инновационному пути развития страны и роста технологической базы экономики осталось всего 2017 - 2014 = 3 года. Мы
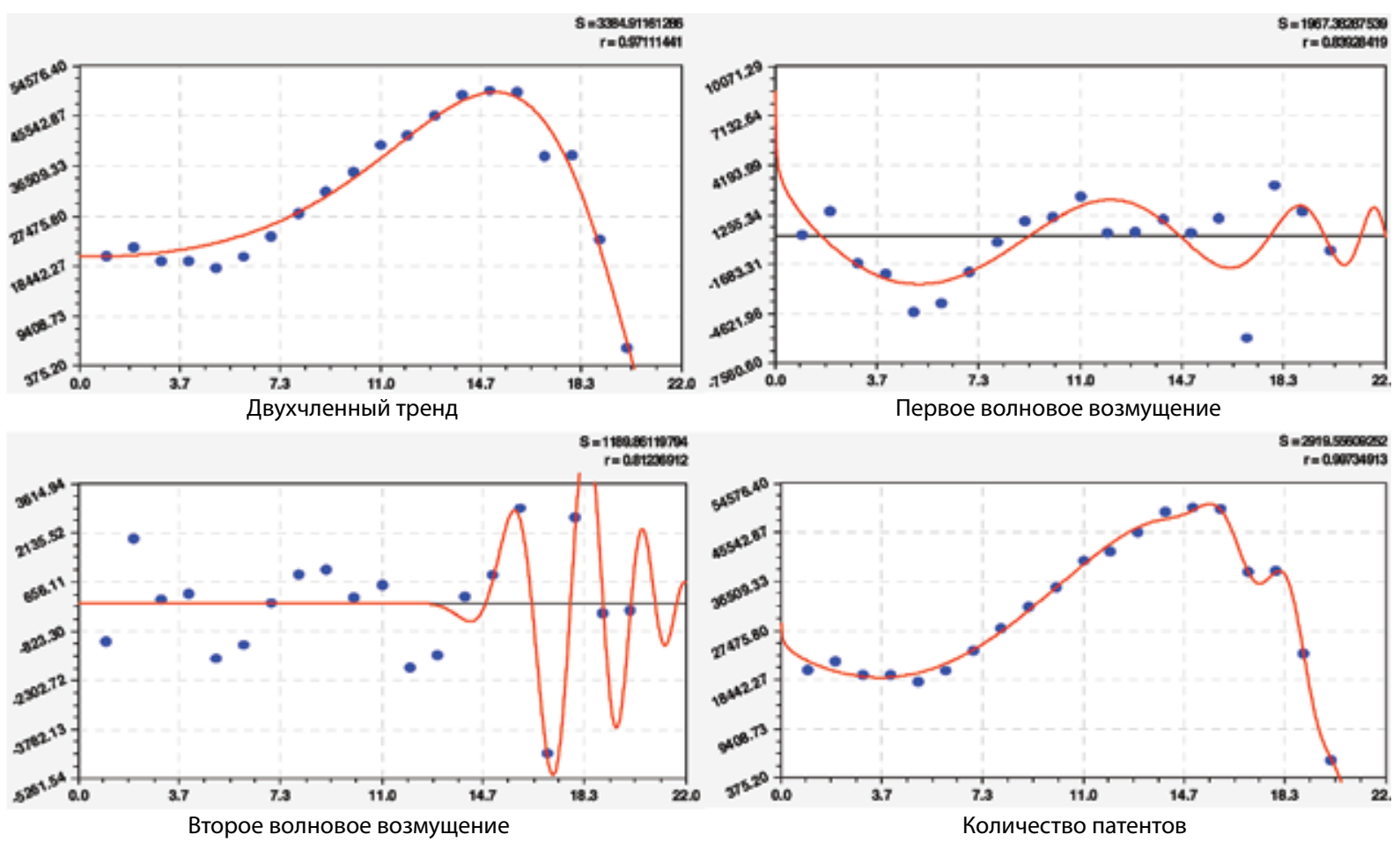

\footnotetext{
${ }_{2}^{2}$ Мазуркин П. М. Динамика российских изобретений // Интеллектуальная собственность. Промышленная собственность. - 2014. - № 2. ${ }^{3}$ P.M. Mazurkin. Factor analysis of the technical level of sibgle-bucket hydraulic excavators // International Journal of Engineering and Innovative Technology (IJEIT), Volume 3, Issue 9, March 2014.
} 
уже «проели» три года из стартового начала объявленной программы модернизации промышленности нашей страны.

В связи с этим вывод напрашивается только один: нужно по существу менять смысл и содержание, т.е. функциональное, конструктивное и параметрическое наполнение новаторства в России. Это изменит и тренд по первому члену уравнения (1). А активное стимулирование новаторства поднимет промышленность страны.

Объем патентования в США. Сразу же отметим, что для этой индустриально развитой страны нужно было взять начало динамического ряда с 1952 г. Тогда сопоставление двух стран по инновационной активности было бы справедливым и более точным, а в промежуток времени в 60 лет уместились бы полтора 40-летних цикла США. Тем более известно, что в СССР новаторство было на достаточно высоком уровне. Для практического прогнозирования нужны добротные данные по обеим странам периода 1952-2012 гг. Тогда удалось бы ежегодно проводить итерацию прогнозных моделей у обеих стран. Для России это очень полезно и дало бы возможность преодолевать психологические барьеры у высших управленцев.

По исходным данным из таблицы 1, которые признаются нами достоверными, была получена (рис. 2) формула:

$N_{R U}=N_{1}+N_{2}+N_{3}+N_{4}$ ，

$N_{1}=103201,34 \exp (0,091960 t)$,

$N_{2}=2,57457 \cdot 10^{-88} t^{189,70807} \exp (-22,86183 t)$,

$N_{3}=A_{1} \cos \left(\pi t / p_{1}+1,63471\right)$,

$A_{1}=6,37169 \cdot 10^{-8} t^{15,79021} \exp (-0,86474 t)$,

$p_{1}=982,60121-48,63460 t^{0,99160}$,

$N_{4}=A_{2} \cos \left(\pi t / p_{2}+0,60643\right)$ ，

$A_{2}=5161,4627 \exp (-0,083873 t)$

$p_{2}=18,46103-15,01260 t^{0,028893}$.

По конструкции формулы (1) и (2) фрактально подобны, но каждая составляющая имеет свои отличи- тельные особенности. По формулам поведение США в инновационной политике осознанное, а России хаотическое.

\section{Нужны комплексные изобретения и другие новшества, направленные на патентную защиту не отдельных видов продукции, а больщих их групп}

Первая составляющая, также как и у России, изменяется по закону экспоненциального роста. Но, в отличие от России, рост плавный, и происходит с качественными изменениями по циклам. Если брать три точки в 1992 (единица), 2012 и 2030 годах, то темпы роста объемов патентования в США будут (по отношению к 1992 г.) 6,3 и 32,9. Сравнение у России с этим началом кризиса дает темпы роста 17,1 и 245000. Такие сверхвысокие темпы показывают хороший отклик российских новаторов (именно они должны составит в будущем элиту России) на необходимость подъема экономики страны. Но сравнение с 1982-м, 1972-м или даже с 1952 г. дало бы куда более надежные для российских прогнозов результаты моделирования.

Второй и последующие члены статистической модели (1) или (2), как правило, показывают антропогенное (в общем случае экзогенное) влияние каких-то факторов на изучаемый процесс. Сравнение моделей (1) и (2) показывает, что для России вторая составляющая - это кризисный провал по закону показательного роста, а в США происходило осознанное позитивное стрессовое возбуждение новаторов по биотехническому закону ${ }^{4}$. Как правило, общий тренд по двум составляющим из формулы (1) присущ поведению организмов и их популяций.

Сразу же возникает вопрос: сколько же лет продолжается это возбуждение? Расчеты показали, что его полуцикл был 7 лет с 1997 по 2004 гг. с максимумом 20139 шт. в 2000 г. Затем начался мировой кризис

${ }^{4}$ См.: Мазуркин П.М. Решение 23-й проблемы Гильберта. Междисциплинарные исследования в области математ. моделирования и информатики. Матер. 3-й научно-практ. internet-конф. - Ульяновск: SIMJET, 2014.; Мазуркин П. М. Вейвлет-анализ кризисной динамики курса рубля // Maтер. 3-й научно-практ. internet-конф. - Ульяновск: SIMJET, 2014; P.M. Mazurkin. Factor analysis of the technical level of sibgle-bucket hydraulic excavators // International Journal of Engineering and Innovative Technology (IJEIT), Volume 3, Issue 9, March 2014. 

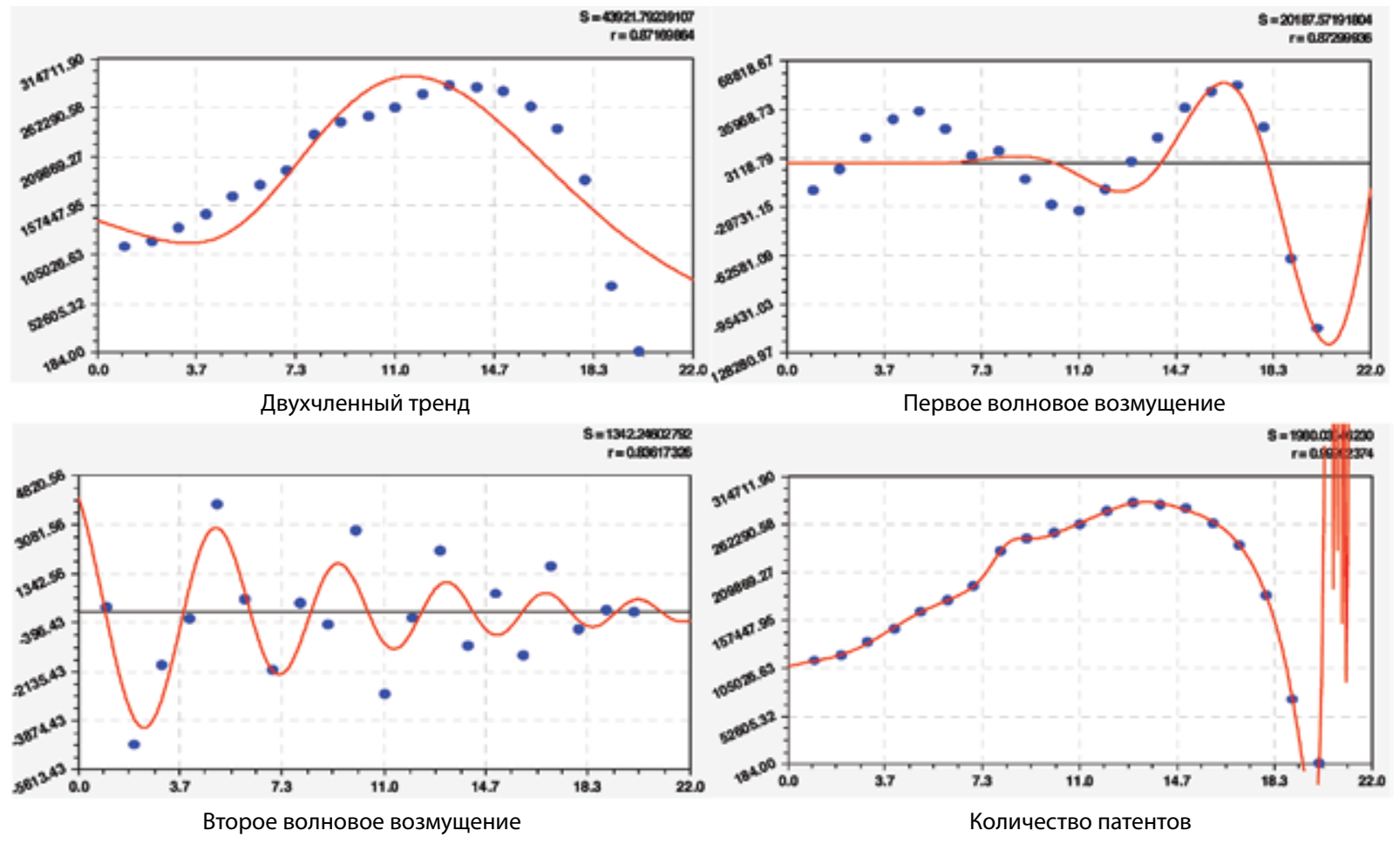

Рис. 2. Графики динамики количества патентов в США за 1992-2012 г2.

и этот второй член уравнения (2) не участвует в расчетах. Тогда получается, что стрессовое возбуждение показывает циклический характер динамики изучаемого показателя. Поэтому тренд, как и положено теоретически, получает с 2004 г. только одну первую составляющую по закону экспоненциального роста.

Наиболее опасно для США первое волновое возмущение с амплитудой по биотехническому закону. Полный цикл волны инновационной активности занимает период с 1996-го по 2035 г., т.е. длина волны равна 40 лет. В этом цикле отрицательные значения приходятся на 1996-2013 гг. (полупериод равен 18 лет) с кризисным максимумом в 2012 г. 648117 патентов. На положительные значения показателя по прогнозу придется полупериод в 22 года с 2013-го по 2035 г. при максимуме +486202 патента в 2014 г.

Это означает, что в США осознанно меняется сама доктрина новаторства. Поэтому в ближайшие годы здесь следует ожидать новую технологическую революцию. В ней меньше места будет патентам существующего типа. Их заместят комплексные изобрете- ния и другие новшества, направленные на патентную защиту не отдельных видов продукции, а больших их групп. Ведь крупные корпорации, накопив до 100000-400000 патентов за десятилетия, уже давно защитили свою продукцию на мировых рынках (точнее сказать, изначально транснациональные корпорации возникали в тяжелой конкурентной борьбе между запатентованными новшествами).

Вторая волна возмущения как раз показывает уход с рынков продукции старого типа, основанного на частичных патентах. Снижение амплитуды колебания происходит при циклах с периодичностью в 2-4 года. Практически становится малозаметно (всего 704 патента в год) влияние второй волны уже B 2012 г.

Сравнение формул (1) и (2) также показывает, что США и Россия имеют очень различимые периоды колебания патентной активности. Причем в нашей стране управление происходит не будущими обстоятельствами, а по результатам прошлых обстоятельств. Период колебания в 1992 г. в России был по двум колебаниям равным 2 7,24097 14,5 и 12,3 года, а в США, соответственно, 1965,2 и 36,9 года. Для 
обеих стран период колебания уменьшается, т.е. колебание происходит с увеличением частоты. Для 2012 г. были уже другие периоды колебания: для России 4,7 и 2,4 года, а для США - 34,1 и 2,1 года.

Отношение показателей двух стран. Этот относительный показатель $N_{R U} / N_{U S A}$ характеризует способность России догнать США по инновационному развитию.

После идентификации была получена (рис. 3) формула:

$N_{R U} / N_{U S A}=S_{1}+S_{2}+S_{3}$,

$S_{1}=0,21309 \exp (-0,026834 t)$,

$S_{2}=2,54634 \cdot 10^{-57} t^{43,71854}$,

$\varsigma_{3}=A \cos (\pi t / p+1,47168)$,
$A=0,54900 \exp \left(-1,5648 t^{0,17515}\right)$.
$p=12,09484-0,00023313 t^{3,12803}$

Уравнение содержит три положительных члена. Но первый член показывает спад инновационной активности в нашей стране по отношению к США (1992-2102 гг. в 1,7 раза, а к 2030 г. в 2,8 раза).

При условии, что в инновационной политике России и США за 2012-2030 гг. ничего в технической политике не изменится, по второму члену (3) произойдет неестественный показательный рост России по отношению к США. Он начался с 2011 г., и поэтому возникает вопрос: точны ли данные [1] за последние два года по двум странам? Особое недоверие вызывают статистические данные 2012 г., когда в России
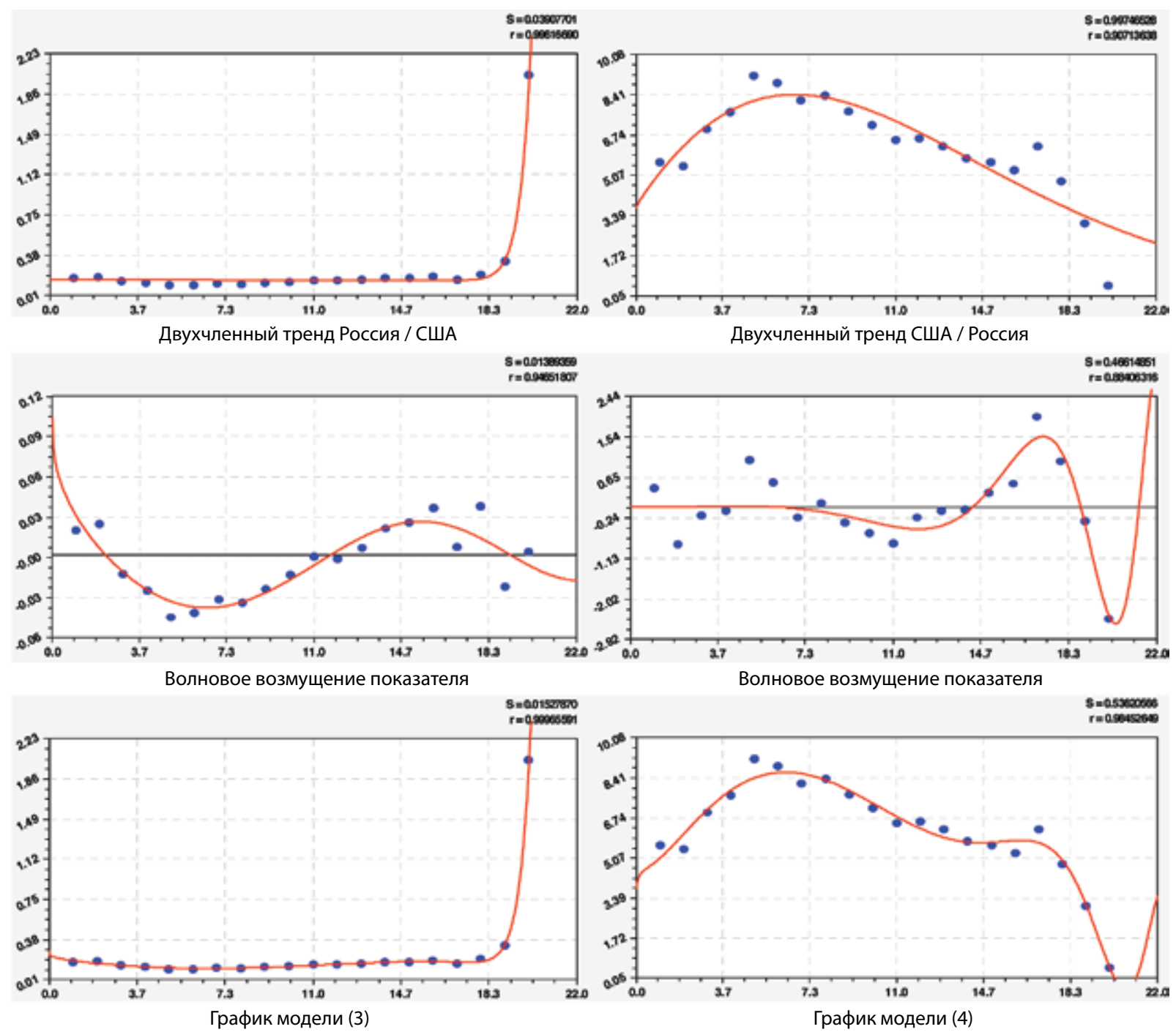
патентов в сравнении с США становится больше в 2,04 раза. А в 2011 г. было только 34\% от уровня США.

Однако по волне возмущения видно, что российские новаторы учащают свое инновационное поведение (повышение полупериода с 12,09 года в 1992 г. до 9,36 года в 2012 г. и далее до 0 в 2024 г, а до 2030 г. колебание становится даже отрицательным).

Отношение результатов патентования США по отношению к России. После идентификации была (рис. 3) получена формула вида:

$N_{\text {RU }} / N_{U S A}=\xi_{1}+\xi_{2}+\xi_{3}$,

$\xi_{1}=3,83136 \exp (-0,97532 t)$,

$\xi_{2}=3,63675 t^{0,64388} \exp \left(-0,0077041 t^{1,92130}\right)$,

$\xi_{3}=A \cos (\pi t / p+0,98118)$,

$A=0,093069 t^{1,07024}$,

$p=14,39566-0,0020912 t^{2,67193}$.

Снова присутствуют три позитивных члена. При этом получается, что по первому члену происходит спад отношения $N_{U S A} / N_{R U}$ (с 3,83 в 1992 г. до нуля в 1998 г.). После 1998 г. первая составляющая равна нулю. Эта закономерность означает только одно: дефолт в нашей стране позволил США полностью игнорировать прошлые советские патенты, в особенности на изобретения.

Вторая составляющая по биотехническому закону показывает сложившийся с 1992 г. по 2030 г. интерес в США к объему патентования в России. Максимум 9,18 $N_{\text {USA }} / N_{R U}$ пришелся на 1999 г. Затем отношение $N_{U S A} / N_{R U}$ плавно убывает до нуля после 2030 г. Тогда получается, что если в инновационной политике двух стран ничего не изменится, то у формулы (4) после 2030 г. останется только волновая составляющая.

Колебательное возмущение США по отношению к России начинается с нуля в 1992 г. и медленно будет наращиваться по амплитуде в соответствии с показательным законом. При этом периодичность колебания уменьшится с 28,8 года в 1992 г. до 16,3 года в 2012 г. и дойдет до нуля в 2020 г. После 2020 г. ожидается отрицательное значение показателя, т.е. у США прогнозируется возникновение негативного отношения к инновационной политике России. При этом, как видно из общего графика на рисунке 4, США после 2014 г. будет наращивать свой объем па- тентования и после 2017 г. в этой стране патентов на новшества будет гораздо больше, чем в России.

Разница между США и Россией. Этот показатель $N_{U S A}-N_{R U}-$ необходим для оценки баланса инновационной политики между двумя странами. Была получена (рис. 3) устойчивая закономерность вида

$N_{U S A}-N_{R U}=N_{\Delta 1}+N_{\Delta 2}+N_{\Delta 3}$,

$N_{\Delta 1}=78861,97 \exp (0,1959 t)$,

$N_{\Delta 2}=-1,77783 t^{4,37463}$,

$N_{\Delta 3}=A \cos (\pi t / p+0,037440)$,

$A=-8,16171 \cdot 10^{-127} t^{160,37146} \exp (-9,04672 t)$,

$p=93,31691-7,20136 t^{0,83001}$.

Двухчленный тренд снова противоречивый: по первому члену Россия никогда (из-за экспоненциального закона роста как бесконечномерной математической функции) не догонит США в количестве патентов. А по кризисному второму члену по показательному закону происходит ускоряющееся замедление разницы $N_{U S A}-N_{R U}$ между США и Россией. Эвристическое толкование может появиться после моделирования за 60 и более лет.

\section{В нашей стране управление происходит не будущими обстоятельствами, а по результатам прошлых обстоятельств}

Кризисная (отрицательный знак перед составляющей модели) волна возмущения появляется только с 2003 г. И она закончится в 2018 г. При этом максимальная амплитуда в 31676 патентов у колебания приходится на 2000 г. Полупериод снизится с 93,3 лет в 1992 г. до 6,8 лет в 2012 г. и после 2014 г. приобретает отрицательное значение. По данным таблицы 1 максимум разницы 240618 патентов был в 2005 г., а после 2012 г. прогнозируется превышение российских патентов над американскими патентами.

\section{Кратность достижения Россией объема патентова-} ния США. Последний показатель $K=\left(N_{U S A}-N_{R U}\right) / N_{R U}$ ориентирован на необходимость идти вдогонку США хотя бы в валовом сборе новшеств. По фактическим данным из таблицы 1 была получена (рис. 4, тренд аналогичен рисунку 3) трехчленная формула вида: 
$K=K_{1}+K_{2}+K_{3}+K_{4}$

$K_{1}=4,04875 \mathrm{exp}(0,10378 t)$,

$K_{2}=-0,010829 t^{2,65058}$,

$K_{3}=A_{1} \cos \left(\pi t / p_{1}+0,82636\right)$,

$A_{1}=-0,93420 \exp (0,049835 t)$,

$p_{1}=9,20109-0,0017331 t^{2,68372}$,

$K_{4}=A_{2} \cos \left(\pi t / p_{2}+0,60535\right)$,

$A_{2}=-0,50602 \exp \left(0,010728 t^{1,71390}\right)$,

$p_{2}=5,39291-0,0014911 t^{2,41616}$.

Здесь все три составляющие, после первого члена, отрицательные (кризисные). По первому члену в идее закона экспоненциального роста Россия с годами все больше будет отставать от США по объему патентования. Но этому росту отставания
России помешают три процесса по 2, 3 и 4 членам модели (6).

Вторая составляющая показывает кризис в самой США по показательному закону. Причем с 2008 г. этот нарастающий кризис начинает преобладать над первой составляющей. Первая (медленно) и вторая (быстро) волны кризисного возмущения нарастают по амплитуде. При этом полупериоды колебаний (9,2 и 5,4 года в 1992 г.) уменьшаются (3,8 и 3,3 года в 2012 г.). Первая волна нулевой полупериод получает к 2017 г, а вторая - к 2022 г. Потому частота колебательного возмущения нарастает, и если не будет коренных изменений в инновационной системе США, то вероятен коллапс по количеству патентов.
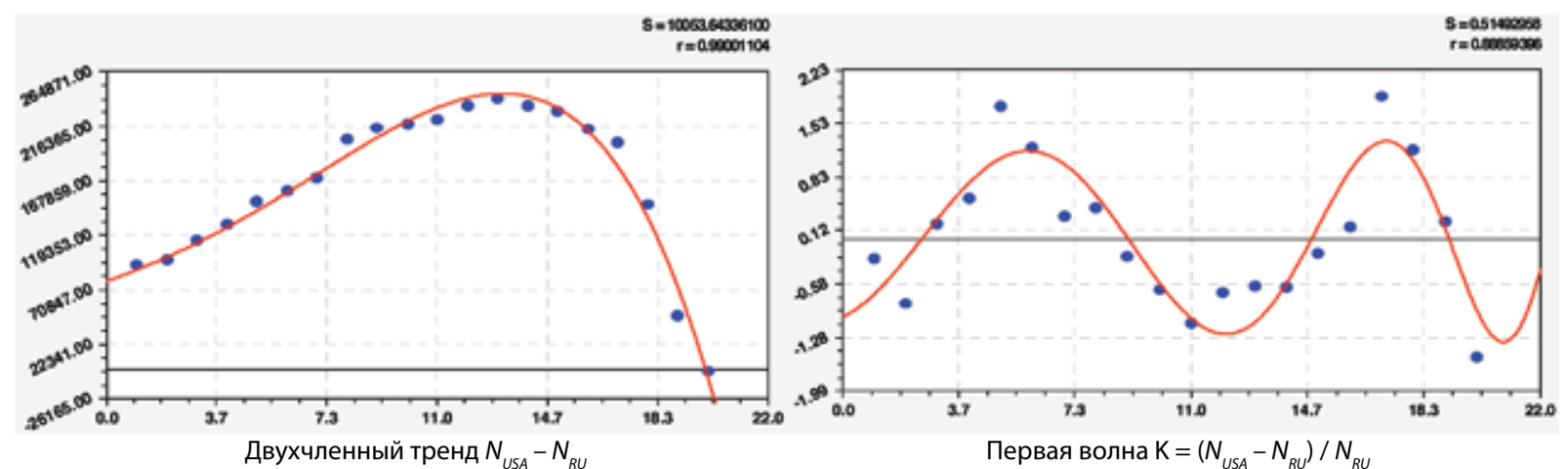

$S=70200000005$ $r=0$ aresesen
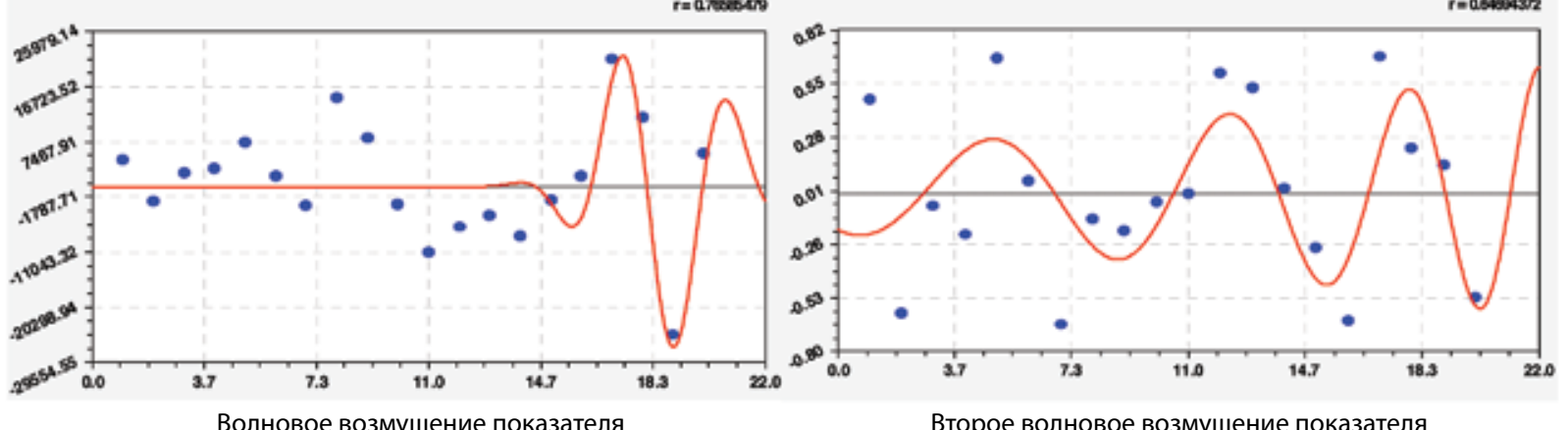

$S=6 \pi$ somatser Второе волновое возмущение показателя
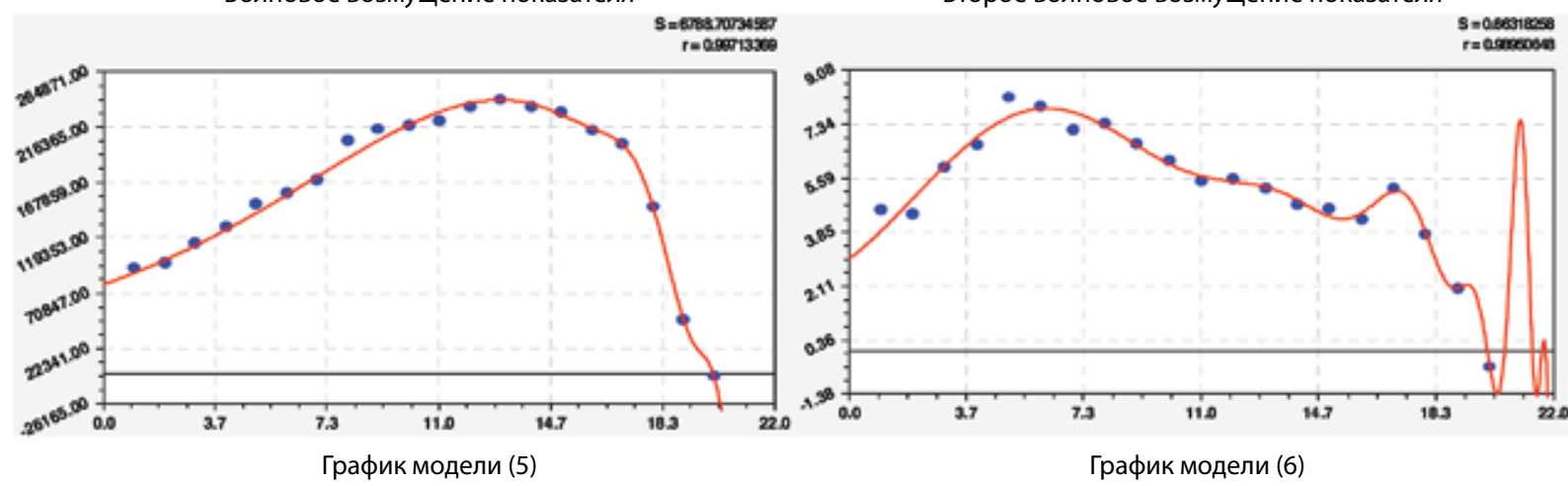
Заключение. Короткие ряды статистических данных [1] не позволили автору настоящей статьи дать точные количественные прогнозы. Чтобы системные кризисы не влияли на результаты прогноза, необходимо строить динамические ряды показателей начиная с 1952 г. Тогда появятся тренды, преодолевающие кризисные периоды ${ }^{5}$. На настоящий момент лишь ясно, что США и Россия, причем каждая посвоему, переживают кризисные времена.

${ }^{5}$ Мазуркин П.М. Вейвлет-анализ кризисной динамики курса рубля // Матер. 3-й научно-nракт. internet-конф. - Ульяновск: SIMJET, 2014.

\section{ЛИТЕРАТУРА:}

1. А. Айгинин, А. Номоконов. Патентная активность: Россия и США // Ин-теллектуальная собственность.

Промышленная собственность. - 2013. - № 10. 